\title{
STUDIES ON ESTERIFYING ACTIVITY OF CHOLESTEROL-ESTERASE
}

\author{
YUJI SUEYOSHI
}

Department of Biochemistry, School of Medicine

Keio University, Tokyo, Japan

NOBORU FUKUO and KAZUHEI EBINA

\section{Laboratory of Yokosuka Municipal Hospital, Yokosuka, Japan}

(Received for publication February 5, 1969)

According to Thannhauser ${ }^{1}$ and Cook, ${ }^{2}$ the rate of intestinal absorption of cholesterol is low when given alone, whereas it is elevated when given with fat. On the other hand, Sperry et $a l^{3}$ and Swell et al ${ }^{4}$ have demonstrated the existence of esterases which catalize the esterification of cholesterol in the pancreatic juice and the intestinal mucosa. Furthermore, Sakamaki ${ }^{5}$ has shown that the absorption of cholesterol is facilitated when given in the esterified form as compared with in the free form. It is apparent from these reports that cholesterol-esterase (esterification) is important in the absorption of cholesterol. However, the detailed information about the nature of the esterase remained to be explored.

In addition, the activity of cholesterol-esterase in the adrenal glands is augmented in the cholesterol fed animals. It is not clear whether the esterification can occur in the adrenal glands or the preformed ester is transported from extra-adrenal tissues in the above circumstances. Therefore the esterifying activity of cholesterol-esterase in the adrenal glands was also investigated. 


\section{EXPERIMENTAL METHODS}

All the experiments were performed with albino rats of non-pure strain, weighing about $150 \mathrm{~g}$, except for the ascorbic acid deficiency experiments where guinea-pigs were used. The experimental procedures described by Yamamoto $e t a l^{6}$ and Swell et al4 were followed. Esterase was prepared from liver, pancreas, mucosa of small intestine (duodenum) and pooled adrenal glands of rats. One and a half milliliter of $50 \%$ glycerolphosphate buffer solution ( $\mathrm{pH} \mathrm{6.6)} \mathrm{was} \mathrm{added} \mathrm{to} 0.5 \mathrm{~g}$ of the tissue, making volume $2.5 \mathrm{ml}$, homogenized for $2 \mathrm{~min}$, shaken for 1 hour, and centrifuged for $5 \mathrm{~min}$ at 2,500 rpm, and the supernatant enzyme solution was obtained.

The enzyme solutions from liver, pancreas and intestine were diluted 2, 3 , and 4 times, respectively. In each experiment, the reaction mixture contained $7.5 \mathrm{mg}$ of cholesterol, $16.5 \mathrm{mg}$ of oleic acid (or fat), $0.1 \mathrm{ml}$ of the diluted enzyme solution, and toluol. The mixture was incubated at $37^{\circ}$ for 24 hours. Sterol was determined by the Zak method. ${ }^{7}$ The amount of esterified sterol was determined by precipitating free sterol as digitonide and the residual sterol was determined, and the percentage of esterified fraction among the total sterol was calculated. The enzyme activity was expressed as percent esterification of sterol.

\section{RESULTS}

Experiment I. Studies on the Esterifying Activity of Hepatic, Pancreatic, and Intestinal Cholesterol-Esterases.

1. Influence of fats on the esterifying activity of cholesterol-esterases.

According to the experimental data on Pancreatin by Sakamaki, 5 the esterifying activity of cholesterol-esterase is much greater when oleic acid is used than when palmitic or stearic acid is used. Therefore, the authors conducted experiments on the hepatic, pancreatic, and intestinal cholesterolesterases to ascertain whether the activity differs when fatty acids of various iodine numbers were used. The results are shown in Table 1.

As shown in Table 1, activity of the hepatic esterase was so low that the difference due to the kind of fat was difficult to be recognized. The pancreatic and the intestinal esterases, however, showed higher activities with fats of greater iodine numbers. For example, with linseed iol, having an iodine number of 172, the extent of sterol esterification in the presence of the intestinal esterase was $87.7 \%$, whereas with beef fat, having an iodine number 
Table 1

Influence of fats on esterifying activity of cholesterolesterases from tissues of rats (Average of 4 animals)

\begin{tabular}{l|c|c|c|c}
\hline \hline \multirow{2}{*}{ Kind of fat } & \multirow{2}{*}{$\begin{array}{c}\text { Iodine number } \\
\text { of fat }\end{array}$} & \multicolumn{3}{|c}{ Esterifying activity of cholesterole-esterases* } \\
\cline { 5 - 5 } & 172 & Liver & Pancreas & Intestine \\
\hline Linseed oil & 115 & 6.6 & 71.3 & 87.7 \\
Sesame oil & 158 & 2.2 & 70.7 & 85.3 \\
Liver oil & 81 & 7.1 & 69.3 & 79.8 \\
Olive oil & 98 & 1.3 & 74.9 & 73.5 \\
Peanut oil & 108 & 9.7 & 64.6 & 72.4 \\
Rice oil & 120 & 6.2 & 66.8 & 71.8 \\
Soya-bean oil & 102 & 1.3 & 68.2 & 68.1 \\
Fish oil & 92 & 4.4 & 60.7 & 54.5 \\
Whale oil & 52 & 4.9 & 60.1 & 45.8 \\
Beef fat & 95 & 4.9 & 57.1 & 25.9 \\
Chaulmoogra oil & 0 & 7.8 & 55.1 & 20.2 \\
Butyrin & & & & \\
\hline
\end{tabular}

* Percent esterification of cholesterol.

of 52, it was only $42.9 \%$. Exceptions were olive oil (iodine number, 81 ), with which esterase activity was relatively high, esterification in the presence of the intestinal esterase being $73.5 \%$, and chaulmoogra oil (iodine number, 95), with which esterase activity was relatively low, percent esterification in the same conditions being only 25.4 .

\section{Table 2}

Influence of kind of fatty acid on the esterifying activity of cholesterol-esterase from rat intestine

\begin{tabular}{l|c}
\hline Fatty acid & $\begin{array}{c}\text { Esterifying activity of intestinal } \\
\text { cholesterol-esterase* }\end{array}$ \\
\hline Saturated fatty acids: & 38.2 \\
Stearic acid & 46.2 \\
Palmitic acid & 6.5 \\
Capric acid & 5.7 \\
Butyric acid & \\
Unsaturated fatty acids : & 81.6 \\
Oleic acid & 79.3 \\
Linoleic acid & 76.9 \\
Elaidic acid &
\end{tabular}

* Percent esterification of cholesterol. 
2. Influence of the kind of fatty acid on the esterifying activity of cholesterol-esterase.

In this experiment, activity of the cholesterol-esterase from intestinal mucosa of rats was examined using unsaturated or saturated fatty acids.

It is apparent from Table 2 that with stearic and palmitic acids, among saturated fatty acids, the percentage of esterification in the presence of the intestinal esterase was relatively low, that is, 38.2 and 46.2 , respectively, and with short chain fatty acids, such as capric and butyric acids, it was very low, esterification being only 5 or $6 \%$. In the case of unsaturated fatty acids, however, activities were high, esterification being 18.6, 79.3 and $76.9 \%$ with oleic, linoleic and elaidic acids, respectively.

3. Esterification of phytosterols with cholesterol-esterases.

Although Schoenheimer et al l,9,10 reported that phytosterols are not absorbed from the intestine, Sakamaki5 found that they are well absorbed if they exist in the esterified form. Thus the authors examined the esterifying activities of the pancreatic and the intestinal esterases, using ergosterol, sitosterol and stigmasterol and oleic acid as substrates. The results are shown in Table 3.

Table 3

Percent esterification of phytosterols with cholesterol-esterases (Average of 4 experiments)

\begin{tabular}{l|c|c}
\hline \hline Phytosterol & Esterifying activity of cholesterolesterases \\
\cline { 2 - 3 } & Pancreas & Intestinal mucosa \\
\hline Ergosterol & 38.2 & 34.4 \\
Sitosterol & 62,3 & 59.1 \\
Stigmasterol & 43.5 & 33.1 \\
\hline
\end{tabular}

As shown in Table 3, any of these phytosterols can also be esterified with the pancreatic and the intestinal esterases to an appreciable extent.

4. Influence of adrenalectomy on the esterifying activity of cholesterolesterases.

The experiment by Sakamaki ${ }^{5}$ indicated that cholesterol is more readily absorbed from the intestine when ingested in the esterified form than in the free form, and that the absorption of cholesterol is markedly reduced after adrenalectomy. The present experiment was conducted to ascertain whether the reduction in absorption of cholesterol after adrenalectomy is due to the reduced esterification. Bilaterally adrenalectomied rats given $1 \%$ saline were 
used. The results are shown in Table 4.

Table 4

Influence of adrenalectomy on esterifying activity of cholestrol-esterases (Average of 3 experiments)

\begin{tabular}{l|c|c|c}
\hline \multirow{2}{*}{ Substrate } & \multicolumn{3}{|c}{ Esterifying activity of cholesterol-esterases* } \\
\cline { 2 - 4 } & Liver & Pancreas & Intestine \\
\hline Olive oil & 6.8 & 75.8 & 68.5 \\
Oleic acid & 8.8 & 78.7 & 75.2 \\
\hline
\end{tabular}

* Percent esterification of cholesterol.

No remarkable decrease in esterifying activity was noted in any of the esterases used.

5, Influence of ascorbic acid on the esterifying activity of cholesterolesterases.

Sueyoshi and Ebina11 found that the amount of esterified cholesterol in the adrenal glands is markedly decreased in ascorbic acid deficiency. In the present study the authors examined the influence of ascorbic acid on activities of the pancreatic and the intestinal cholesterol-esterases. Guinea-pigs weighing about $300 \mathrm{~g}$ were fed bean curd refuse and greens as a normal diet and cooked bean curd refuse without greens as an ascorbic acid deficient diet. Positive occult blood in feces was taken as an index of ascorbic acid deficiency. The experiment started one week after the deficiency symptoms developed.

Table 5

Influence of ascorbic acid on esterifying activity of cholesterol-esterases (Average of 3 experiments)

\begin{tabular}{l|c|c|c|c}
\hline \multirow{2}{*}{$\begin{array}{l}\text { Experimental } \\
\text { conditions }\end{array}$} & \multicolumn{3}{|c}{ Esterifying activity of cholesterol-esterases* } \\
\cline { 2 - 5 } & \multicolumn{2}{|c|}{ With oleic acid } & \multicolumn{2}{|c}{ With olive oil } \\
\cline { 2 - 5 } & Pancreas & Intestine & Pancreas & Intestine \\
\hline Normal & 77.0 & 81.5 & 79.7 & 73.8 \\
\hline As. a. def.** & 78.2 & 19.2 & 76.2 & 14.0 \\
\hline $\begin{array}{l}\text { As. a. def. } \\
\text { As. a. 20 } \mathrm{mg} \text { inj. }\end{array}$ & 77.8 & 49.2 & 77.2 & 42.2 \\
\hline $\begin{array}{l}\text { As. a. def. } \\
\text { As. a. 50 mg inj. }\end{array}$ & 74.6 & 81.3 & 72.5 & 76.3 \\
\hline
\end{tabular}

* Percent esterification of cholesterol.

** Ascorbic acid deficient. 
The results of the experiments are presented in Table 5 .

It will be noted from Table 5 that activity of cholesterol-esterases in the normal guinea-pigs did not differ significantly from that in the normal rats, and that the activity was markedly decreased in the intestine from ascorbic acid deficient guinea-pigs.

In guinea-pigs, maintained on the ascorbic acid deficient diet, decrease in activity of the intestinal esterase became less marked when $20 \mathrm{mg}$ of ascorbic acid was injected daily, and the normal value of activity was completely restored when the daily doses of ascorbic acid was $50 \mathrm{mg}$. Activity of the intestinal esterase, as described above, was decreased markedly in ascorbic acid deficiency, while that of the pancreatic esterase remained unchanged. This was thought to be attributable to ascorbic acid content which might be decreased in the intestine and not in the pancreas. In order to confirm the above possibility, content of ascorbic acid of the pancreas and the intestinal mucosa was determined in normal and ascorbic acid deficient guineapigs.

Table 6

Ascorbic acid content in pancreas and intestine of guinea-pigs (Average of 4 animals) (mg/100g)

\begin{tabular}{l|c|c}
\hline $\begin{array}{l}\text { Conditions of } \\
\text { animal }\end{array}$ & \multicolumn{2}{|c}{ Amount of ascorbic acid (mg/100 g) } \\
\cline { 2 - 3 } Normal & Pancreas & Small intestine \\
\hline $\begin{array}{c}\text { Ascorbic acid } \\
\text { deficient }\end{array}$ & 15.2 & 22.7 \\
\hline
\end{tabular}

As shown in Table 6, in normal guinea-pigs ascorbic acid content in the pancreas was $15.2 \mathrm{mg} / 100 \mathrm{~g}$ and that in the intestinal mucosa was $22.7 \mathrm{mg}$ / $100 \mathrm{~g}$, whereas in the ascorbic acid deficient guinea-pigs it was markedly decreased in both the pancreas and the intestine to only $0.02 \mathrm{mg} / 100 \mathrm{~g}$.

6. Influence of lecithin and choline on the activity of cholesterol-esterases.

According to Nieft et $a l,{ }^{12}$ hydrolysis of cholesterol-esters with intestinal esterase is accelerated by the existence of soya lecithin. The experiment was performed by the authors to see if the above is also true for esterification. In addition, Sakamaki ${ }^{5}$ reported that cholesterol is absorbed more readily in the esterified form, and Tidwelli: ${ }^{13}$ has shown that the absorption of cholesterol is augmented by supplementation of choline and fat. Thus, the effect of 
choline on the esterification of cholesterol was investigated. Soya lecithin and choline were added to the incubation mixture to give the final concentration of $1 \%$, respectively. The results are shown in Table 7 .

Table 7

Influence of lecithin and choline on esterifying activity of cholesterol-esterases (Average of 4 experiments)

\begin{tabular}{l|c|c|c|c}
\hline \multirow{3}{*}{ Addition } & \multicolumn{3}{|c}{ Esterifying activity of cholesterol-esterases* } \\
& \multicolumn{2}{|c|}{. With oleic acid } & \multicolumn{2}{|c}{ With olive oil } \\
\hline Lecithin & 75.3 & Intestine & Pancreas & Intestine \\
\hline Choline & - & 77.8 & 73.8 & 75.2 \\
& Pancreas & - & 72.3 & 73.2 \\
\hline
\end{tabular}

* Percent esterification of cholesterol.

It is noted from Table 7 that addition of neither lecithin nor choline to the mixture had any influence on esterification.

7. Influence of $\mathrm{KCN}$, malonic acid, and 2,4-dinitrophenol on the activity of cholesterol-esterases.

Tekeikin et all4 reported that $\mathrm{KCN}$, malonic acid, and 2,4-dinitrophenol (DNP) have an inhibitory effect on fatty acid incorporation into the tissue phospholipid. In this report they referred to the involvement of esterification of fatty acids with coenzyme $A$ in the presence of ATP in the process of phospholipid synthesis. Furthermore, Mukherjee et all5 mentioned that esterification of fatty acids with coenzyme $A$ in the presence of ATP also occurs during formation of cholesterol-esters by the aid of hepatic cholesterolesterase. The authors conducted an experiment to investigate the effect of the above 3 substances on esterifying activity of the pancreatic and the intestinal cholesterol-esterases. The results are shown in Table 8.

As will be seen in Table 8 , the activity of the pancreatic esterase was almost unchanged upon addition of $\mathrm{KCN}$ at a level of $0.075 \%$, whereas that of the intestinal esterase was slightly lowered. At $0.6 \%$ level of $\mathrm{KCN}$, however, the activity of both the pancreatic and the intestinal esterase was markedly lowered.

The activity of the intestinal esterase was lowered with malonic acid (1\%), whereas that of the pancreatic esterase was slightly elevated.

As for DNP, the activity of the pancreatic and the intestinal esterases was slightly lowered when added at a level of $0.3 \%$. 
Table 8

Influence of KCN, malonic acid and DNP on esterifying activity of cholesterol-esterases (Average of 4 experiments)

\begin{tabular}{l|c|c|c|c}
\hline \multirow{2}{*}{ Addition } & \multicolumn{3}{|c}{ Esterifying activity of choresterol-esterases* } \\
\cline { 2 - 5 } & \multicolumn{2}{|c|}{ With oleic acid } & \multicolumn{2}{c}{ With olive oil } \\
\cline { 2 - 5 } & Pancreas & Intestine & Pancreas & Intestine \\
\hline KCN: & 72.5 & 50.6 & 73.3 & \\
$0.075 \%$ & 71.2 & 46.3 & 70.1 & 46.4 \\
$0.1 \%$ & 68.2 & 44.2 & 63.0 & 41.5 \\
$0.15 \%$ & 11.4 & 18.5 & 18.0 & 14.6 \\
$0.6 \%$ & 87.3 & 53.8 & 85.7 & 50.3 \\
\hline Malonic acid 1\% & 66.5 & 54.5 & 60.3 & 48.3 \\
\hline DNP 0.3\% & 74.8 & 80.3 & 71.4 & 78.1 \\
\hline Control & & & & \\
\hline
\end{tabular}

* Percent esterification of cholesterol.

Experiment II. Studies on Esterifying Activity of the Adrenal CholesterolEsterase.

1. Esterifying activity of the adrenal cholesterol-esterase from animals fed on normal or cholesterol supplemented diet.

Esterifying activity of the adrenal cholesterol-esterase from rats fed on a normal diet was $6.7 \%$ as shown in Table 9. This figure was so small that it was difficult to determine if cholesterol-esters were actually formed in the adrenal glands. Accordingly, an experiment was performed as follows.

Sueyoshi and Ebina ${ }^{11}$ found that the amount of cholesterol-ester in the adrenal glands of rats increases markedly upon supplementation of cholesterol to the diet. This led to an assumption by authors that esterifying activity had been increased in the above conditions, and an experiment was designed to verify that assumption.

Rats were fed on a diet supplemented with cholesterol at a level of $0.3 \mathrm{~g} / \mathrm{day}$, and the activity of the adrenal esterase was determined on the 5th, 10th and 15th day. As shown in Table 9, the activity expressed as percent esterification was $8.2 \%$ on the 5 th day, slightly increased to $10.4 \%$ on the 10th day, and further increased to $21.7 \%$ on the 15 th day.

It is well known that ACTH augments the adrenocortical function. Thus, ACTH was injected daily in a dose of $1 \mathrm{mg}$ for the last 3 days of the 15 
Table 9

Esterifying activity of adrenal cholesterol-esterase

\begin{tabular}{l|c|c}
\hline \multicolumn{1}{c|}{ Fxperimental conditions } & Esterifying activity* & Number of animal \\
\hline Normal diet & 6.7 & 15 \\
\hline Cholesterol diet: & & \\
5th day & 8.2 & 6 \\
10th day & 10.4 & 5 \\
15th day & 21.7 & 7 \\
\hline Cholesterol diet and ACTH & 34.5 & 12 \\
\hline Cholesterol diet and vitamin $\mathrm{B}_{1} \& \mathrm{C}$ & 49.4 & 9 \\
\hline Exposure to cold at $4^{\circ} \mathrm{C}$ for $10 \mathrm{hrs}$ & 23.2 & 4 \\
\hline Exposure to cold at $4^{\circ} \mathrm{C}$ for $10 \mathrm{hrs}$, & 19.1 & 4 \\
and then at room-temperature for & & \\
\hline h hrs & &
\end{tabular}

* Percent esterification of cholesterol.

day-period of the cholesterol diet, and the esterifying activity of the adrenal esterase was determined. As shown in Table 9, the percent esterification thus obtained was 34.5 , which was higher than that obtained with the cholesterol diet without ACTH.

Furthermore, it has been reported ${ }^{16}$ that the amount of cholesterol in the adrenal glands is decreased in vitamin $B_{1}$ deficient animals, and Sueyoshi et $a l^{11}$ found that the amount of ascorbic acid and cholesterol in the adrenal glands diminishes during ascorbic acid deficiency. Thus, vitamin $B_{1}$ (1 mg per day) and ascorbic acid (5 mg per day) were given along with the cholesterol diet for 15 days and the activity of the adrenal esterase was determined. As shown in Table 9, percent esterification was 49.4.

Exposure of rats to cold at $4^{\circ} \mathrm{C}$ has generally been known to decrease markedly adrenal cholesterol and ascorbic acid. An experiment was carried out on the assumption that activity of the esterase could be augmented to restore the level of cholesterol-ester.

As presented in Table 9, esterification was $23.2 \%$ when the animals were exposed to $4^{\circ} \mathrm{C}$ for 10 hours, and $19.1 \%$ when exposed first to $4^{\circ} \mathrm{C}$ for 10 hours and then to room temperature for 3 hours, i.e., the activity was slightly enhanced in both instances. 


\section{SUMMARY AND DISCUSSION}

Experiments were performed on the esterifying activity of cholesterolesterases from liver, pancreas, intestinal mucosa, and adrenal glands. The activity was expressed as percent esterification of cholesterol added to the medium.

\section{Experment I.}

- 1) The experiment on the relationship between the activity of cholesterolesterase and the kind of fat used as substrate revealed that, in general, the larger the iodine number of fat, the higher was the activity of esterase, except that there was no marked difference in the esterase activity noted between cases in which linseed oil (iodine number, 172) and olive oil (iodine number, 81) were used, and that the activity was low with chaulmoogra oil (iodine number, 91).

2) As regards the relationship between the kind of fatty acid and the activity of esterase, the activity was much higher in the case of unsaturated faity acid than in the case of saturated fatty acid. This cannot be explained by the fact that the unsaturated fatty acid is liquid and the saturated fatty acid is solid, because in the case of elaidic acid, an isomer of oleic acid, the activity was high although it is solid.

3) Although phytosterols have been said to be less absorbable from the intestine, ${ }^{8-10}$ Sakamaki $^{5}$ demonstrated that a significant amount of them is absorbed if they are in esterified form. The authors investigated the esterification of ergosterol, sitosterol and stigmasterol and found that they can be esterified to a considerable extent. Among the phytosterols studied, sitosterol was esterified to the highest percentage, i.e., $59.1 \%$ with the intestinal esterase and $62.3 \%$ with the pancreatic esterase.

4) The experiment by $\mathrm{Sakamaki}^{5}$ revealed that adrenalectomy reduces the absorption of cholesterol. This led us to determine the esterifying activity of pancreas and intestine after adrenalectomy. Hardly any effect was seen. 'I'hus, it was indicated that reduction in absorption of choleaterol after adrenalectomy is not due to impairment of esterification.

5) Sueyoshi and Ebina ${ }^{11}$ found that cholesterol-ester formation in the adrenal glands is diminished in ascorbic acid deficiency. In the present study, an investigation was undertaken to see if the activity of the pancreatic and the intestinal esterases is also affected by ascorbic acid deficiency in guinea-

pigs. The result is that the activity of the pancreatic esterase was unchanged, 
whereas that of the intestinal esterase was markedly reduced. In the latter case, diminished activity of the intestinal esterase was restored to the normal level upon injection of ascorbic acid. Since the ascorbic acid content was markedly reduced in both the pancreas and the intestine, the unchanged activity of the pancreatic esterase in ascorbic acid deficiency is ascribed to higher resistance to the deficiency as compared to the intestinal esterase. This is inconsistent with the view presented by Swell et alli that both the esterases are of identical nature.

6) The presence of lecithin or choline had no influence on the activity of the pancreatic and the intestinal esterases.

7) The activity of the pancreatic and the intestinal esterases was lowered by KCN or 2,4-dinitrophenol. Malonic acid depressed the activity of the intestinal esterase but it slightly augmented that of the pancreatic esterase. This indicates a difference in nature between the two esterases.

Experiment II.

1) In rats fed on a normal diet, the esterifying activity of cholesterolesterase in the adrenal glands was as low as $6.7 \%$.

2) In rats fed on a cholesterol diet, activity of the esterase increased day by day and reached $21.7 \%$ on the 15 th day of the diet.

3) In rats fed on a cholesterol diet and injected with ACTH (1 mg/day) for 15 days, activity of the esterase increased to $34.5 \%$.

4) In rats fed on a cholesterol diet and injected with vitamin $B_{1}$ ( $1 \mathrm{mg}$ / day) and ascorbic acid ( $5 \mathrm{mg} /$ day) for 15 days, the esterase activity inrceased to $49.4 \%$.

5) In rats exposed to $4^{\circ} \mathrm{C}$ for 10 hours, the esterase activity was $23.2 \%$, and in those exposed to $4^{\circ} \mathrm{C}$ and then to room temperature for 3 hours, it was

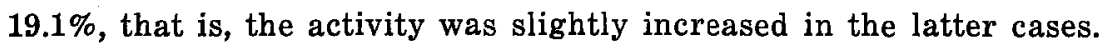

6) The above data indicate that the esterifying activity of cholesterolesterase in the adrenal glands is low on a normal diet, but is increased upon injection of ACTH, vitamin $B_{1}$ or ascorbic acid along with a cholesterol diet. Thus, it is concluded that cholesterol-ester in the adrenal glands can be formed in the adrenal glands themselves and that the activity of cholesterolesterase in the adrenal glands is increased when the adrenocortical function is augmented. 


\section{REFERENCES}

1. Thannhauser, S.J. (1924) Cholesterol Metabolism. Deut. Arch. Klin. Med. 141: 290-311.

2. Cook, R.P. (1938) Cholesterol Metabolism I. Acids Apparently Concerned in the Metabolism of Cholesterol. Biochem. J. 32: 1191-1199.

3. Sperry, W.M. and Brand, F.C. (1941) A Study of Cholesterol Esterase in Liver and Brain. J. Biol. Chem. 137: 377-387.

4. Swell, L. and Treadwell, C.R. (1950) Cholesierol Esterases II. Characterization of the Esterifying Cholesterol Esterase of Pancreatin. J. Biol. Chem. 182: 479487.

5. Sakamaki, T. (1956) Absorption of Dietary Sterols. J. Keio Med. Soc. 33: 386394. (in Japanese)

6. Yamamoto, R.S., Goldstein, N.P., and Treadwell, C.R. (1949) Cholesterol Esterases I. Preparation of Substrate Mixture and Characterization of the Hydrolytic Cholesterol Esterase of Pancreatin. J. Biol. Chem. 180: 615-621.

7. Zak, B., Moss, N., Boyle, A.J., and Zlatkis, A. (1954) Reactions of Certain Unsaturated Steroids with Acid Iron Reagent. Anal. Chem. 26: 776-777.

8. Schönheimer, R. (1929) Ủber die Bedeutung der Pflanzens.erine für den c̈ierischen Organismus. Z. physiol. Chem. 180: 1-16, 24-37.

9. Schönheimer, R. und Yuasa, D. (1929) Speicherungsversuche mit Sitosterin. Z. physiol. Chem. 180: 5-16, 1929; Verfügt der tierische Organismus über Pflanzensterinesterasen? Ibid. 19-23.

10. Schönheimer, R., Behring, H., und Hummel, R. (1930) Ueber die Spezifität der Resorption von Sterinen, abhängig von ihrer Konstitution. Z. physiol. Chem. 192: 117-123.

11. Sueyoshi, Y. and Ebina, K. (1965) Effect of Ascorbic Acid on Increase in Esterified Cholesterol in Adrenal Glands of Guinea Pigs Fed on Cholesterol Diet. Keio J. Med. 14: 189-192.

12. Nieft, M.L. and Deuel, H.J., Jr. (1949) Studies on Cholesterol Esterases I. Enzyme Systems in Rat Tissues. J. Biol. Chem. 177: 143-150.

13. Tidwell, H.C. (1956) Effect of Choline, Methionine and Ethionine on Fat Absorption. J. Nutr. 58: 569-578.

14. Jekeikin, L.A. and Weinhouse, S. (1954) Studies of the Incorporation of Palmitate-1-C14 into Tissue Lipides in Vitro. Arch. Biochem. Biophys. 50: 134-147.

15. Mukherjee, S., Kunitake, G., and Alfin-Slater, R.B. (1958) The Esterification of Cholesterol with Palmitic Acid by Rat Liver Homogenates. J. Biol. Chem. 230: 91-96.

16. Verzár, F. und Péter, F. (1924) Die Hypertrophie der Nebennierenrinde bei Mangel an Vitamin B. (Avitaminose und Inkretion) II. Mitteilung, Pflüger's Arch. ges. Physiol. 206: 659-665.

17. Swell, L., Byron, J.E., and Treadwell, C.R. (1950) Cholesterol Esterases. IV. Cholesterol Esterase of Rat Intestinal Mucosa. J. Biol. Chem. 186: 543-548. 